\title{
Resorbable membrane of polyethylene glycol in Wistar rats for guided bone regeneration - Experimental study
}

\author{
Sousa $\mathrm{JA}^{1}$, Correia $\mathrm{F}^{2^{*}}$, Escobar $\mathrm{T}^{1}$, \\ Portela $A^{3}$, Vasconcelos $\mathrm{M}^{4}$, Faria de \\ Almeida $R^{5}$ \\ Affiliations: \\ 1. Master of Oral Surgery, Faculty of Dental \\ Medicine of Porto, Porto, Portugal. \\ 2. PhD in Oral Surgery, Faculty of Dental Medicine \\ of Porto, Porto, Portugal. \\ 3. Assistant Professor, Faculty of Dental Medicine \\ of Porto, Porto, Portugal. \\ 4. Associate Professor with Aggregation, Faculty \\ of Dental Medicine of Porto, Porto, Portugal. \\ 5. Cathedratic Professor, Faculty of Dental \\ Medicine of Porto, Porto, Portugal. \\ Corresponding author: \\ Francisco Correia \\ franciscodcorreia@gmail.com
}

\begin{abstract}
Purpose: The aim of the present study was (1) to test whether or not the application of an in situ formed synthetic hydrogel, made of polyethylene glycol (PEG) used as a resorbable membrane for guided bone regeneration, will result in more amount of bone regeneration compared with an uncovered defect and (2) to evaluate if it can prevent the soft-tissue ingrowth into alveolar defects.

Materials and Methods: Two critical size defects were created in seven Wistar rats. In the right side, an in situ formed hydrogel PEG membrane (Straumann MembraGel) was applied into the defect and the left one was kept empty as a control. After 60 days, animals were sacrificed and the calvarial bone was removed. The area of newly formed bone was determined by histomorphometrical analysis. For statistical analysis, the Mann-Whitney-U test was applied to model the amount of new bone formation.

Results: The quantitative histomorphometric analysis obtained a percentage of newly formed bone for the test defects of $61,8 \%+/-22,2 \%$ and $53,8 \%+/-22,9 \%$ in the control group. The observed differences were not statistically significant.

Conclusions: The experimental PEG membrane was biocompatible and prevented soft-tissue ingrowth. There were no statistically significant differences between the groups.
\end{abstract}

\section{KEYWORDS}

Bone defects, bone regeneration, membranes, polyethylene glycol, Wistar rats 


\section{INTRODUCTION}

Guided bone regeneration (GBR) and guided tissue regeneration (GTR) have become very common procedures with the exponential growth of implantology. These procedures are mainly used for the treatment of peri-implant bone defects and periodontal issues as well bone augmentation before or simultaneously with implants placement.

There is a wide range of membranes' materials of different origins, compositions and presentations. Nowadays, resorbable membranes made of collagen have become the most used membranes in several clinical situations. However, resorbable membranes present poor mechanical properties that jeopardize space maintenance and when used without a space filling grafting material tend to collapse into the osseous defect space. ${ }^{7}$ Another disadvantage of the membranes is that they are produced in standardized sizes and need to be adapted manually to the morphology of the receptor site. ${ }^{8}$ Thus, the individualization of size and shape is time-consuming and a complicated procedure, which limits the use of membranes in daily clinical practice. ${ }^{9}$

Liquid membrane formed in situ offer several advantages, particularly for more complex morphologies and difficult access places. ${ }^{10}$ Several studies have evaluated the hydrogel membrane made of polyethylene glycol (PEG) for bone regeneration. ${ }^{11,12}$

The capabilities of this new hydrogel have been tested for the last ten years. It was proved to be biodegradable and usable as a membrane for GBR in non-critical defects. ${ }^{8,10,12-19}$

The aim of the present study is to verify if the application of an in situ formed synthetic hydrogel made of PEG, used as a resorbable membrane for guided bone regeneration, will result in more quantity of bone regeneration compared with an uncovered defect.

\section{MATERIAL AND METHODS}

The following experimental study was approved by the Portuguese Agency for Agriculture and Veterinary in accordance with article 8 of ordinance no. 1005/92 of October 23, 1992, concerning the treatment of experimental animals.

Seven Wistar rats (20 weeks) weighing between 318 and $365 \mathrm{~g}$ were used. The animals were kept throughout the experimental period in isolated cages placed in a properly programmed cabinet in terms of temperature, humidity, air flow, pressure, and cycles of light / dark. Appropriate water was provided and were fed ad libitum.

Two standardized critical defects were created in the calvaria bone, approximately $5 \mathrm{~mm}$ diameter each, through a standardized slit for this purpose.

General anesthesia was performed, in a chamber in which were subjected to inhalation with isoflurane (ISOFLO ${ }^{\circ}$, Veterinary Esteve). They were then anesthetized with one intra-peritoneal injection of a 1:1 preparation of $7.5 \mathrm{mg} / \mathrm{Kg}$ of Ketamine (Imalgène ${ }^{\circ}$ 1000, Merial) and 5mg/kg Xizalina (Rompum, Bayer HealthCare). After recording animals' body weight, the intervention area was disinfected with an iodine solution (Betadine', cutaneous solution $100 \mathrm{mg} / \mathrm{ml}$, MEDA Pharma).

An incision was made over the sagittal calvaria at the midline suture using $\mathrm{N}^{\circ} 15$ blade scalp, extending from the coronal suture to the parietal-occipital suture.

After detachment of the skin and subcutaneous tissue through retractors and forceps dissection proceeded to the detachment of the periosteum, to reflect the external bony plate and access the parietal bones.

Circular bone defects were performed in bilateral parietal bones, about $5 \mathrm{~mm}$ in diameter and $1.8 \mathrm{~mm}$ distance between them,

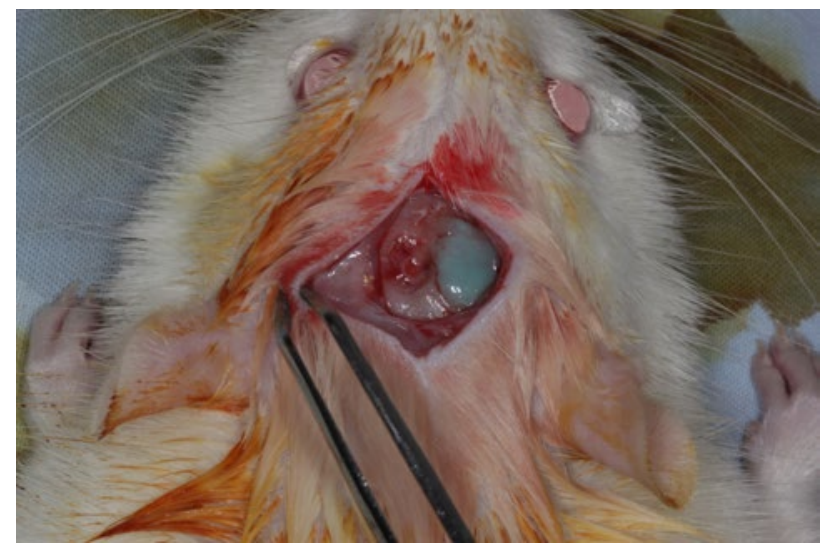

Figure 1. Clinical image of the test and control sides

through bur mounted in the handpiece with low rotation and with sterile saline ( $\mathrm{NaCl} 0.9 \%{ }^{\circ}, 250 \mathrm{ml}$, Braun) irrigation. Care was taken to avoid injury the dura or reaching the sagittal sinus.

In the defect created on the right side of the calvaria was placed polyethylene glycol hydrogel membrane (Straumann MembraGel', Straumann AG) and the left side was left untreated, as defect control (Figure1).

The PEG hydrogel layer was as thin and evenly as possible. It was found that after a short time, approximately 90 seconds, the hydrogel, which initially showed strong green color and translucency of a typical gel, became light green gaining stiffness and opacity to the touch, signals that polymerization was complete. The PEG hydrogel was applied at least 2-3mm beyond the margins of the defect. This membrane requires no fasteners. The closure of the wound was done with the tissue sutured using simple stitches with polyglycolic acid coated $4 / 0$ (Safi ${ }^{\circ} 4 / 0$, Braun) resorbable suture braided, starting with the suture of the periosteum, then the skin was also sutured.

\section{Histological preparation}

Animals were sacrificed two months later. Radiographs of the skull were made to observe whether there were differences in the bone density of defects using an X-ray unit (Trophy Radiology, CCX Digital 70kV, Vincennes, France).

The sample containing the defect sites was removed from the skull and the control defects were separated from the test. The samples were kept in $4 \%$ formaldehyde in phosphate buffer, $\mathrm{pH}$ $=7.4$ for $48 \mathrm{~h}$ (attachment) and were sent to carry out routine histology to the Dental Anatomy Laboratory (Faculty of Dental Medicine University of Porto, Portugal).

Samples were conducted in alcohol increasing dehydration (ethyl alcohol 70\%, 80\%, 90\% and 100\%), remaining in each vial 48 hours (in the case of the latter solution was replaced 3 times, with periods of 48 hours each). They were then impregnated with methyl methacrylate (Merck Schuchardt OHG - Merck KGaA, Hohenbrunn, Germany). After impregnation, the samples were included in the same product after polymerization, were cut with a diamond disc in a microtome (Accutom - Struers A/S, Ballerup, Denmark), in sections of about $150200 \mu$ m-thick, after being polished (Struers DAP-8, Struers A / S, Ballerup, Denmark), reaching approximately $40 \mu \mathrm{m}$. Afterwards, samples were stained with Solocrom and mounted on glass slides, bonded with Permacol (Ind UV Permacol', Adhesive 327/3, Permacol Ind., The Netherlands), polymerized with ultraviolet light. The placement of the cover glass over the specimen followed the same procedure. 


\section{Histomorphometric Analysis}

The sections were analyzed on a microscope Leica DMLB ${ }^{\circ}$ Type 020-519010 LB30T (Leica Microsystems, Wetzlar GmbH, Heerbrugg, Germany) to which was attached a digital camera Leica DFC295 (Leica Microsystems Ltd, Heerbrugg, Germany) with Leica lens 506083 to 2.5x increase. For quantitative analysis, the slides were photographed and measurements were made in the areas of defect and regeneration by a blinded operator, using a digital pen and table [41] (Wamboo \& Pen Touch Wacom Company, Ltd.) and the Leica Application Suite Version 3.5.0 (Leica Microsystems Ltd, Switzerland).

The following parameters were measured: total defect area, area of new bone formation and the quantity of soft tissues present. The results were presented as a percentage of the total area of the defect.

\section{Statistical Analysis}

This is a pilot study in an animal model with rats. The sample size was chosen for convenience.

The results were analyzed using SPSS 21.0 (SPSS, Chicago, IL). A Shapiro-Wilks test was performed since is more accurate for small samples $(n<30)$ aiming to test the normality of distribution. As the sample was small and did not have a normal distribution, it has been chosen to use nonparametric tests, performing the Mann Whitney $U$ test, which compares the difference between the medians of two independent groups.

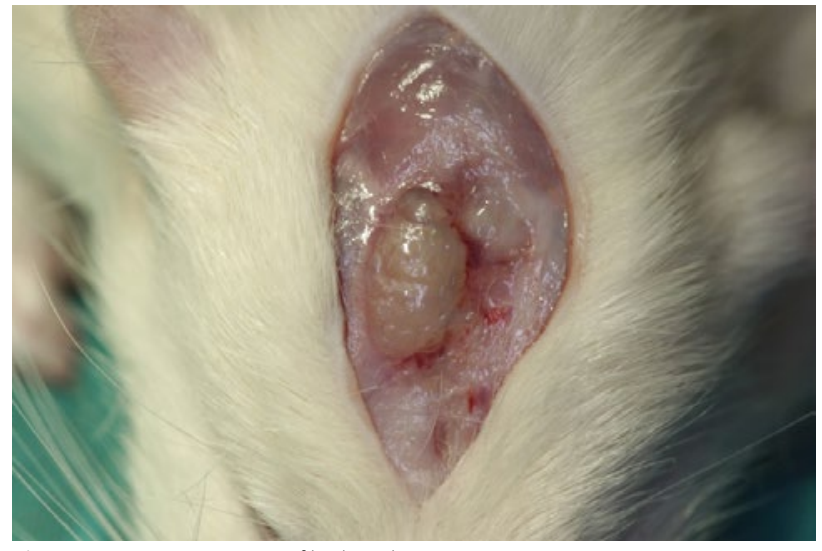

Figure 2. Macroscopic view of hydrogel persistence

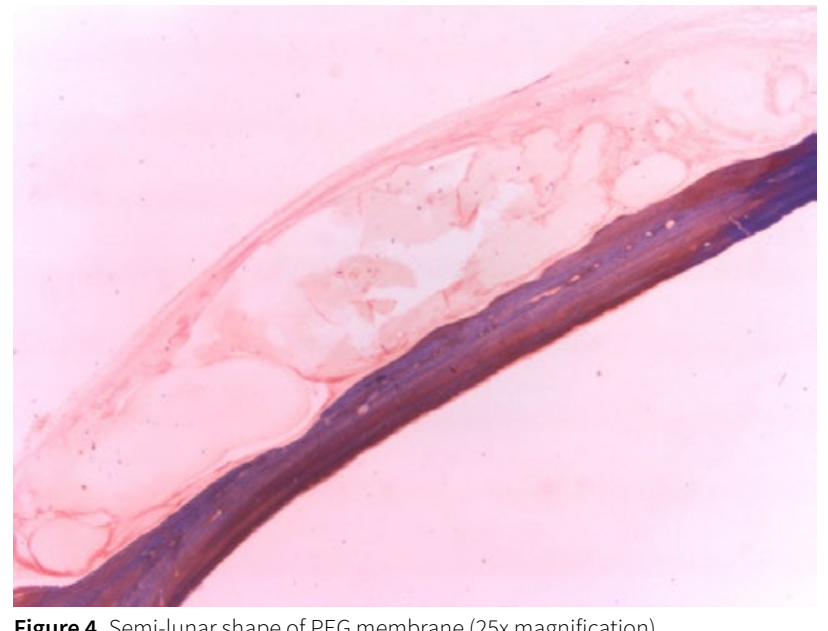

The following hypothesis were considerate:

$\mathrm{HO}$ - There is no difference between using membrane or their absence;

$\mathrm{H} 1$ - There is difference between the use of membrane or its absence.

\section{RESULTS}

The animals were healthy throughout the study period. They all had an increase in weight and have not been registered any postoperative infection or healing problems. At the time of sacrifice were not detected any signs of local inflammation.

Clinical analysis

After tissues removal the persistence of the hydrogel membrane of polyethylene glycol was found macroscopically in six of the seven samples (Figure 2).

\section{Radiographic analysis}

Through an X-ray beam perpendicular to the calvaria were unable to obtain any difference between the groups (Figure 3).

\section{Descriptive Histology (morphological analysis)}

The PEG hydrogel kept its shape during the 60 days of regeneration. The membrane had, in most cases (six of the seven), a semi-lunar shape was observed and in general terms was intact (Figure 4). In relation to the soft tissue, the hydrogel presented a smooth surface with few irregularities.

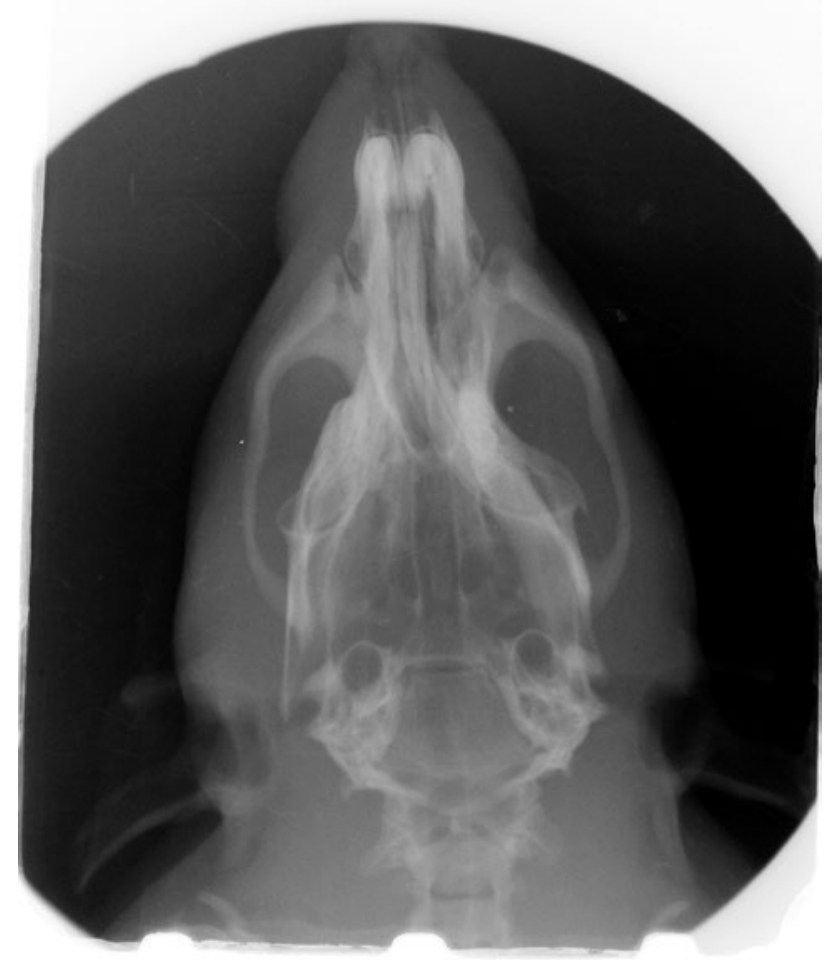

Figure 3. Skull x-ray 
The hydrogel was surrounded by a large number of fibroblasts and inflammatory cells. Between these layers, cells of subcutaneous fat were observed in bundles of collagen fibers tend parallel to the surface of the hydrogel, having, however, any irregularity in their arrangement (Figure 5 and 6).

Inside, the PEG hydrogel was almost in direct contact with the newly formed bone and connective tissue containing fibroblasts, blood vessels and some inflammatory cells. The new bone formation was limited only by the membrane and calvaria. Osteoblasts can be observed in the area of new bone formation signalized with arrows in Figure 7.

Compared with the control, it can be seen that the defects filled with the hydrogel of PEG, had a greater bone growth (Figure 8) even of it wants statistically significative and despite the fact non-existent tent promoted by some pre-produced membranes. It was observed that in all defects, the membrane PEG functioned as a barrier, preventing cellular infiltration.

Almost no bone regeneration was found in the defects without membrane. The defects were filled with fibroblasts and inflammatory cells.

\section{Analysis of cell invasion}

Through observation of histological sections, it can be seen that there was no invasion of the soft tissue. The test defects remained filled with the membrane, with sharply defined borders, having checked that bone growth has occurred. In the defects without membrane, there was practically no bone growth, or when present, was residual.

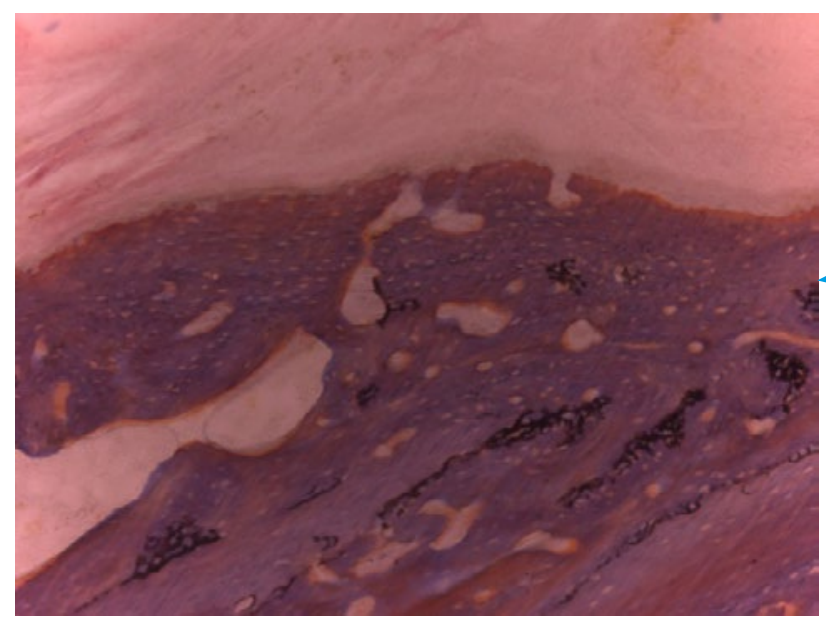

Figure 5. Photomicrograph of defect areas $(\rightarrow$ indicates bone formation) (50x magnification)

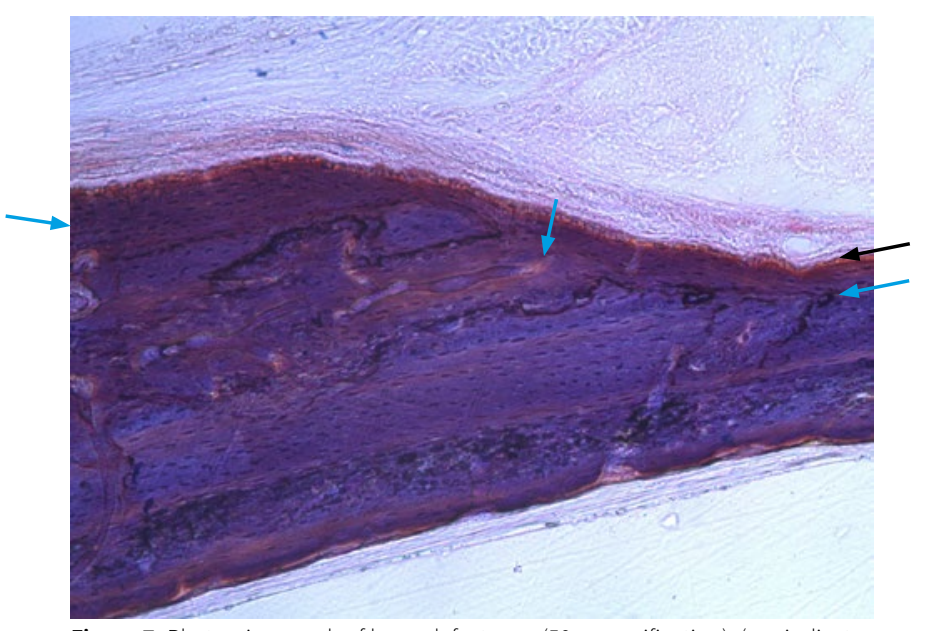

Figure 7. Photomicrograph of bone defect area (50x magnification). essentially a collagen matrix; $\rightarrow$ indicates bone neoformation site)

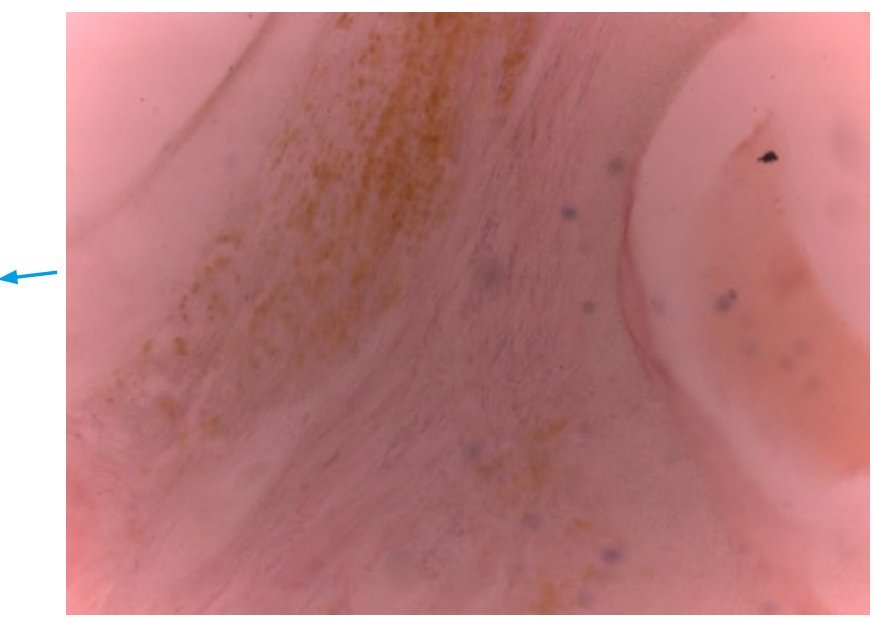

Figure 6. Photomicrograph of defect areas ( ${ }^{*}$ collagen fibers) (50x magnification)

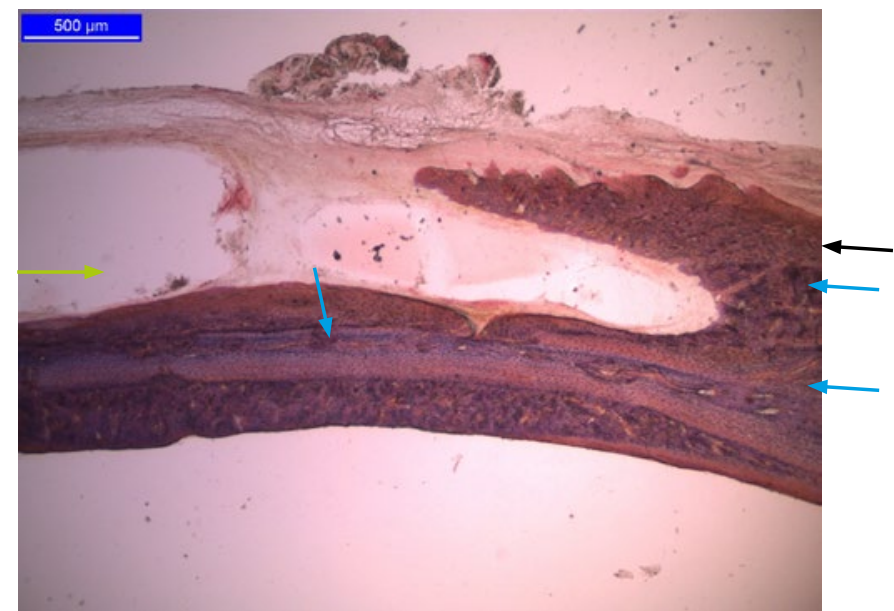

Fig. 8 - Photomicrograph of bone defect (50x) $\rightarrow$ indicates PEG membrane; $\rightarrow$ indicate bone neoformation sites; $\rightarrow$ indicates essentially a collagenous bone matrix) 


\section{Statistical analysis}

Descriptive statistical analysis of the database revealed that the defects without membrane had a median of $41 \%$ of bone regeneration with $22.93 \%$ of a standard deviation. In the defects with a membrane, the median is $64 \%$ with a standard deviation of $22.2 \%$ (Table 1 ).

Table 1. Descriptive statistics of newly formed bone (\%)

\begin{tabular}{|c|c|c|}
\hline \multicolumn{3}{|c|}{ Percentage of Newly Formed Bone } \\
\hline Treatment & $\begin{array}{c}\text { Median } \% \text { new bone } \\
(95 \% \mathrm{Cl})\end{array}$ & St. Deviation \\
With membrane & $\begin{array}{c}64 \% \\
(63,6 \%-64,4 \%)\end{array}$ & $22,2 \%$ \\
\hline $\begin{array}{c}\text { Without } \\
\text { membrane }\end{array}$ & $\begin{array}{c}41 \% \\
(40,56 \%-41,44 \%)\end{array}$ & $22,93 \%$ \\
\hline \multicolumn{2}{|c|}{$\mathrm{Cl}=$ Confidence Interval } \\
\hline
\end{tabular}

To verify the normality of the database a Shapiro-Wilk test was run.

With $p<0,05$, that the groups do not present a normal distribution. Considering $p<0,05$ in the untreated group, the groups do not have a normal distribution. Thus, nonparametric tests were applied using a Mann-Whitney test.

At the Mann-Whitney test, as $p>0.05$, it appears that there are no significant statistically differences between groups, but there is a tendency to have greater bone regeneration in membrane defects.

\section{DISCUSSION}

The use of rats in this study is in agreement with others, trying to evaluate the effectiveness of different types of membranes for bone regeneration or for the study of bone regeneration itself. The critical defect in rats' calvaria is an experimental model for selective bone regeneration. Defects used in this study proved to be critical as demonstrated by reduced or absent bone regeneration in defects without membrane, in accordance with other studies.

The sample of this study was small, as this is a preliminary study whose results may lead to the performance of other experimental work, in order to verify the advantages of using this cell barrier hydrogel over other membranes in guided bone regeneration.

The results of this study demonstrated that the PEG hydrogels function as barrier tissue and can be used as membrane.

The membrane of PEG maintained the original shape during the 60 days of regeneration.

Having regard to the objective of the study, the defects filled with PEG membrane, had greater bone regeneration, however, it was not statistically significant.

It was noted that some of the sections obtained by defects filled with membrane had worse results than others without membrane. This result may be due to the fact that critical defects have been set $(5 \mathrm{~mm})$ and the membrane itself does not make the tent effect. The hydrogel even fills the defect, removing conditions to occur enough regeneration.

Regarding membrane function, PEG molecules with multiple arms of PEG form the hydrogel, more and smaller than those used in matrix systems for the release of bioactive molecules, successfully investigated in preclinical. It was demonstrated that PEG gels, which consist of multi-arm molecules, are considered cellular barriers due to the fact that the distances of the points of crosslinking are significantly smaller than the size of a cell. Histological analysis revealed prevention of cellular penetration in the group with membrane up to 4 months. It was demonstrated that the material PEG was safe, well tolerated and there were no adverse reactions attributed to the material, nor was patients who could not be applied.

The results are also confirmed by previous pre-clinical studies which demonstrate the ability of the membrane to maintain PEG space in order to prevent defects in cellular invasion and angular function as a barrier when accompanied by bone filling material. However, the current study showed that the defect space was occupied by significant quantities of PEG, as described in previous studies. This is due to the fluid nature of the hydrogel in the initial stage upon application of the defect, causing defect filling with the membrane.

Regarding biocompatibility, Jung et al. in 2009, had already demonstrated this ability of PEG hydrogel applications in ROG. In 2007, Jung et al. reported the absence of inflammatory reactions of soft tissue and hard tissue regeneration during intra and extra oral with PEG hydrogels. ${ }^{38}$ Similarly, there has already been shown that the PEG hydrogel membranes formed in situ were able to maintain the necessary space for bone regeneration, but there is such a need of a replacement bone to fill the defect.

Other preclinical studies demonstrate the potential of the PEG membrane as a cell barrier in GBR in combination with or without immediate placement of implants. In a randomized, controlled clinical study of Jung et al. 2009, the membrane of PEG in combination with deproteinized bovine bone mineral was compared with a collagen membrane of porcine origin in combination with that bone in dehiscence defects around implants. The vertical filling of the defect was $94.9 \%$ in the test (PEG) and $96.4 \%$ in the control defects. However, further delays were observed scarring or incomplete due to complications with the soft tissues in cases of the PEG membrane.

One of the major advantages of using PEG membrane is handling and the possibility of clinical application of the membrane directly at the surgical site. Moreover, there is no loss of time by cutting and adaptation of the shape of the membrane, as occurs when using standardized membranes. In studies conducted in humans and animals, was tested a membrane composed of polylactic acid dissolved in $\mathrm{N}$-methyl pyrrolidone as a barrier to regeneration of periodontal tissues lost. Although this material can precipitate from solution in situ by the addition of water 47 , in most studies, a membrane made of this polymer was formed extra-orally before application to the periodontal defect.

The viscosity of the PEG membrane makes this gel indicated for clinical applications that are proposed, without sagging material for adjacent areas. Furthermore, the use of PEG hydrogel as membrane will represent an evolution towards future GBR procedures.

In statistical terms, it appears that there is not a normal distribution of the groups ( $p>0.05$ ), as can be seen by the ShapiroWilks test. The Mann-Whitney test, demonstrate that not reject the null hypothesis that bone regeneration is the same with or without membrane. Hence, there are no significant statistically differences between groups. However, defects covered with membrane results better than uncovered defects. The results indicate that this is a type 2 error, having as probable cause the small sample size.

There were no statistically significant differences between the groups in relation to bone regeneration of rat calvaria defects.

\section{CONCLUSIONS}

The present study demonstrated that the PEG hydrogels function as synthetic membrane formed in situ and can be used as a resorbable cell barrier for 60 days. It was found that 
PEG hydrogel is safe, demonstrating that there is no significant tissue reaction, compared to the unfilled defect. It can be used as a cell barrier functioning as membrane in the GBR, in Wistar rat calvaria critical defects treatment. The density of the hydrogel demonstrated the ability to maintain the shape and resistance to degradation. Histomorphometric analysis showed that there was more bone regeneration at the defect covered with hydrogel membrane than in the defects without membrane. This PEG membrane formed in situ has the potential to meet the requirements for the procedures of the GBR.

As a conclusion, taking into account that this was an exploratory study, the PEG hydrogel membrane might be a valuable alternative in the GBR, requiring, however, a bone replacement material for maintaining the defects that are going to be regenerated. This pilot study also allowed to conclude that the PEG hydrogel presentation of self-mixing syringe, becomes an easy to use tool, supporting the clinical application of a resorbable membrane without the need of prior adjustment. However, further, and future studies with more representative sample are needed to confirm the results of this study.

\section{ACKNOWLEDGEMENTS}

The biomaterials used in this study were provided by Institute Straumann. The remaining costs of this study were supported by the authors.

\section{CONFLICT OF INTEREST}

The authors report no conflicts of interest.

\section{REFERENCES}

1. Hammerle CH, Jung RE. Bone augmentation by means of barrier membranes. Periodontology 2000. 2003;33:36-53.

2. Bunyaratavej P, Wang HL. Collagen membranes: a review. J Periodontol. 2001;72(2):215-29.

3. Zitzmann NU, Naef R, Schärer P. Resorbable versus nonresorbable membranes in combination with Bio-Oss for guided bone regeneration. Int J Oral Maxillofac Implants. 1997 Nov-Dec;12(6):844-52. Erratum in: Int J Oral Maxillofac Implants 1998 Jul-Aug;13(4):576.

4. Hämmerle CH, Brägger U, Schmid B, Lang NP. Successful bone formation at immediate transmucosal implants: a clinical report. Int J Oral Maxillofac Implants. 1998 Jul-Aug;13(4):522-30

5. Jung RE, Glauser R, Schärer P, Hämmerle CH, Sailer HF, Weber FE. Effect of rhBMP-2 on guided bone regeneration in humans. Clin Oral Implants Res. 2003 Oct;14(5):556-68.

6. Moses O, Pitaru S, Artzi Z, Nemcovsky CE. Healing of dehiscence-type defects in implants placed together with different barrier membranes: a comparative clinical study. Clin Oral Implants Res. 2005 Apr;16(2):210-9.Moses O, Pitaru S, Artzi Z, Nemcovsky CE. Healing of dehiscence-type defects in implants placed together with different barrier membranes: a comparative clinical study. Clin Oral Implants Res. 2005 Apr;16(2):210-9.

7. Strietzel FP, Khongkhunthian P, Khattiya R, Patchanee P, Reichart PA. Healing pattern of bone defects covered by different membrane types--a histologic study in the porcine mandible. J Biomed Mater Res B Appl Biomater. 2006 Jul;78(1):35-46.

8. Thoma DS, Halg GA, Dard MM, Seibl R, Hammerle CH, Jung RE. Evaluation of a new biodegradable membrane to prevent gingival ingrowth into mandibular bone defects in minipigs. Clin Oral Implants Res. 2009 Jan;20(1):7-16.

9. Pirhonen EM, Pohjonen TH, Weber FE. Novel membrane for guided bone regeneration. Int J Artif Organs. 2006 Sep;29(9):834-40.

10. Wechsler S, Fehr D, Molenberg A, Raeber G, Schense JC, Weber FE. A novel, tissue occlusive poly(ethylene glycol) hydrogel material. J Biomed Mater Res A. 2008 May;85(2):285-92.

11. Lutolf MP, Hubbell JA. Synthesis and physicochemical characterization of end-linked poly(ethylene glycol)-co-peptide hydrogels formed by Michael-type addition. Biomacromolecules. 2003 May-Jun;4(3):713-22

12. Jung RE, Zwahlen R, Weber FE, Molenberg A, van Lenthe GH, Hammerle CH. Evaluation of an in situ formed synthetic hydrogel as a biodegradable membrane for guided bone regeneration. Clin Oral Implants Res. 2006 Aug;17(4):426-33.

13. Herten M, Jung RE, Ferrari D, Rothamel D, Golubovic V, Molenberg A, Hämmerle CH, Becker J, Schwarz F. Biodegradation of different synthetic hydrogels made of polyethylene glycol hydrogel/RGD-peptide modifications: an immunohistochemical study in rats. Clin Oral Implants Res. 2009 Feb;20(2):116-25.

14. Jung RE, Lecloux G, Rompen E, Ramel CF, Buser D, Hammerle CH. A feasibility study evaluating an in situ formed synthetic biodegradable membrane for guided bone regeneration in dogs. Clin Oral Implants Res. 2009 Feb;20(2):151-61.

15. Jung RE, Hälg GA, Thoma DS, Hämmerle CH. A randomized, controlled clinical trial to evaluate a new membrane for guided bone regeneration around dental implants. Clin Oral Implants Res. 2009 Feb;20(2):162-8.

16. Humber CC, Sándor GK, Davis JM, Peel SA, Brkovic BM, Kim YD, Holmes HI, Clokie CM. Bone healing with an in situ-formed bioresorbable polyethylene glycol hydrogel membrane in rabbit calvarial defects. Oral Surg Oral Med Oral Pathol Oral Radiol Endod. 2010 Mar;109(3):372-84.

17. Ramel CF, Wismeijer DA, Hämmerle CH, Jung RE. A randomized, controlled clinical evaluation of a synthetic gel membrane for guided bone regeneration around dental implants: clinical and radiologic 1- and 3-year results. Int J Oral Maxillofac Implants. 2012 Mar-Apr;27(2):435-41.

18. Zambon R, Mardas N, Horvath A, Petrie A, Dard M, Donos N. The effect of loading in regenerated bone in dehiscence defects following a combined approach of bone grafting and GBR. Clin Oral Implants Res. 2012 May;23(5):591-601.

19. Escobar T, Almeida e Sousa J, Portela A, Vasconcelos M, Faria de Almeida R. The effect of a biphasic calcium phosphate on bone healing: a pilot study in rats. Int J Oral Maxillofac Implants. 2014 Nov-Dec;29(6):1322-31.

20. Verna C, Dalstra M, Wikesjö UM, Trombelli L; Carles Bosch. Healing patterns in calvarial bone defects following guided bone regeneration in rats. A micro-CT scan analysis. J Clin Periodontol. 2002 Sep;29(9):865-70

21. de Brito Bezerra B, Mendes Brazão MA, de Campos ML, Casati MZ, Sallum EA, Sallum AW. Association of hyaluronic acid with a collagen scaffold may improve bone healing in critical-size bone defects. Clin Oral Implants Res. 2012 Aug;23(8):938-42.

22. Notodihardjo FZ, Kakudo N, Kushida S, Suzuki K, Kusumoto K. Bone regeneration with BMP-2 and hydroxyapatite in critical-size calvarial defects in rats. J Craniomaxillofac Surg. 2012 Apr;40(3):287-91

23. Hollinger JO, Kleinschmidt JC. The critical size defect as an experimental model to test bone repair materials. J Craniofac Surg. 1990 Jan;1(1):60-8.

24. Bosch C, Melsen B, Vargervik K. Importance of the critical-size bone defect in testing bone-regenerating materials. J Craniofac Surg. 1998 Jul;9(4):310-6.

25. Schwarz F, Ferrari D, Sager M, Herten M, Hartig B, Becker J. Guided bone regeneration using rhGDF-5- and rhBMP-2-coated natural bone mineral in rat calvarial defects. Clin Oral Implants Res. 2009 Nov;20(11):1219-30.

26. Donos N, Retzepi M, Wall I, Hamlet S, Ivanovski S. In vivo gene expression profile of guided bone regeneration associated with a microrough titanium surface. Clin Oral Implants Res. 2011 Apr;22(4):390-8.

27. Ivanovski S, Hamlet S, Retzepi M, Wall I, Donos N. Transcriptional profiling of "guided bone regeneration" in a critical-size calvarial defect. Clin Oral Implants Res. 2011 Apr;22(4):382-9. 
28. Luvizuto ER, TangI S, Zanoni G, Okamoto T, Sonoda CK, Gruber R, Okamoto R. The effect of BMP-2 on the osteoconductive properties of $\beta$-tricalcium phosphate in rat calvaria defects. Biomaterials. 2011 May;32(15):3855-61. doi: 10.1016/j.biomaterials.2011.01.076. Epub 2011 Mar 3.

29. Toker H, Ozdemir H, Ozer H, Eren K. Alendronate enhances osseous healing in a rat calvarial defect model. Arch Oral Biol. 2012 Nov;57(11):1545-50.

30. Blom EJ, Klein-Nulend J, Yin L, van Waas MA, Burger EH. Transforming growth factor-beta1 incorporated in calcium phosphate cement stimulates osteotransductivity in rat calvarial bone defects. Clin Oral Implants Res. 2001;12(6):609-16.

31. Cacciafesta V, Dalstra M, Bosch C, Melsen B, Andreassen TT. Growth hormone treatment promotes guided bone regeneration in rat calvarial defects. Eur J Orthod. 2001 Dec;23(6):733-40.

32. Mardas N, Stavropoulos A, Karring T. Calvarial bone regeneration by a combination of natural anorganic bovine-derived hydroxyapatite matrix coupled with a synthetic cell-binding peptide (PepGen): an experimental study in rats. Clin Oral Implants Res. 2008 Oct;19(10):1010-5.

33. Issa JP, Pitol DL, Iyomasa MM, Barbosa AP, Defino HL, Volpon JB, Shimano AC, Silva P. Collagen fibers evaluation after rhBMP-2 insertion in critical-sized defects. Micron. 2009 Jul-Aug;40(5-6):560-2.

34. Nyan M, Miyahara T, Noritake K, Hao J, Rodriguez R, Kuroda S, Kasugai S. Molecular and tissue responses in the healing of rat calvarial defects after local application of simvastatin combined with alpha tricalcium phosphate. J Biomed Mater Res B Appl Biomater. 2010 Apr;93(1):65-73.

35. Donos N, Graziani F, Mardas N, Kostopoulos L. The use of human hypertrophic chondrocytes-derived extracellular matrix for the treatment of critical-size calvarial defects. Clin Oral Implants Res. 2011 Dec;22(12):1346-53.

36. Lutolf MP, Weber FE, Schmoekel HG, Schense JC, Kohler T, Müller R, Hubbell JA. Repair of bone defects using synthetic mimetics of collagenous extracellular matrices. Nat Biotechnol. 2003 May;21(5):513-8.

37. Jung RE, Cochran DL, Domken O, Seibl R, Jones AA, Buser D, Hammerle CH. The effect of matrix bound parathyroid hormone on bone regeneration. Clin Oral Implants Res. 2007 Jun;18(3):319-25.

38. Jung RE, Hämmerle $\mathrm{CH}$, Kokovic V, Weber FE. Bone regeneration using a synthetic matrix containing a parathyroid hormone peptide combined with a grafting material. Int J Oral Maxillofac Implants. 2007 Mar-Apr;22(2):258-66.

39. Buser D, Ruskin J, Higginbottom F, Hardwick R, Dahlin C, Schenk RK. Osseointegration of titanium implants in bone regenerated in membrane-protected defects: a histologic study in the canine mandible. Int J Oral Maxillofac Implants. 1995 Nov-Dec;10(6):666-81.

40. Oh TJ, Meraw SJ, Lee EJ, Giannobile WV, Wang HL. Comparative analysis of collagen membranes for the treatment of implant dehiscence defects. Clin Oral Implants Res. 2003 Feb;14(1):80-90.

41. von Arx T, Cochran DL, Hermann JS, Schenk RK, Higginbottom FL, Buser D. Lateral ridge augmentation and implant placement: an experimental study evaluating implant osseointegration in different augmentation materials in the canine mandible. Int J Oral Maxillofac Implants. 2001 May-Jun;16(3):343-54.

42. Wehrhan F, Amann K, Molenberg A, Lutz R, Neukam FW, Schlegel KA. PEG matrix enables cell-mediated local BMP-2 gene delivery and increased bone formation in a porcine critical size defect model of craniofacial bone regeneration. Clin Oral Implants Res. 2012 Jul;23(7):805-13.

43. Aaboe M, Pinholt EM, Hjørting-Hansen E. Healing of experimentally created defects: a review. Br J Oral Maxillofac Surg. 1995 Oct;33(5):312-8.

44. Jepsen S, Heinz B, Kermanie MA, Jepsen K. Evaluation of a new bioabsorbable barrier for recession therapy: a feasibility study. J Periodontol. 2000 Sep; 71(9):1433-40.

45. Garrett S, Polson AM, Stoller NH, Drisko CL, Caton JG, Harrold CQ, Bogle G, Greenwell H, Lowenguth RA, Duke SP, DeRouen TA. Comparison of a bioabsorbable GTR barrier to a non-absorbable barrier in treating human class II furcation defects. A multi-center parallel design randomized single-blind trial. J Periodontol. 1997 Jul;68(7):667-75.

46. Bogle G, Garrett S, Stoller NH, Swanbom DD, Fulfs JC, Rodgers PW, Whitman S, Dunn RL, Southard GL, Polson AM. Periodontal regeneration in naturally occurring Class II furcation defects in beagle dogs after guided tissue regeneration with bioabsorbable barriers. J Periodontol. 1997 Jun;68(6):536-44.

47. Rosen PS, Reynolds MA. Polymer-assisted regenerative therapy: case reports of 22 consecutively treated periodontal defects with a novel combined surgical approach. J Periodontol. 1999 May;70(5):554-61. 